\title{
JOGO SAN SAN COMO RECURSO DIDÁTICO DE APOIO NAS DISCUSSÕES SOBRE NUTRIENTES REGULADORES NO ENSINO FUNDAMENTAL
}

\author{
EL JUEGO SAN SAN COMO RECURSO DIDÁCTICO DE APOYO EN LAS \\ DISCUSIONES ACERCA DE LOS NUTRIENTES REGULADORES EN LA \\ ENSE NANZA FUNDAMENTAL
}

\begin{abstract}
THE SAN SAN GAME AS DIDATIC RESOURCE OF SUPPORT IN THE DISCUSSIONS ABOUT REGULATORY NUTRIENTS IN ELEMENTARY EDUCATION
\end{abstract}

\author{
Bárbara Della ANTONIA ${ }^{1}$ \\ Rodrigo Iwata FUJIWARA ${ }^{2}$ \\ Rosebelly Nunes MARQUES ${ }^{3}$
}

RESUMO: As atividades lúdicas são utilizadas no processo de ensino aprendizagem das diferentes áreas do conhecimento, por promoverem o aprendizado de forma espontânea e divertida. Para a área de Ciências agrárias, a qual é uma área multidisciplinar de estudos que pode ser abordada desde o ensino básico até o ensino superior, há a necessidade de estudos que visem à elaboração de recursos didáticos. Dessa forma, este estudo objetivou o desenvolvimento de um jogo didático na área de ciências agrárias voltado para o ensino fundamental, cuja estratégia é auxiliar na compreensão dos conteúdos relacionados à composição química de alimentos, com foco em nutrientes reguladores. O jogo SAN SAN foi aplicado e avaliado com alunos do ensino fundamental de uma escola pública, trazendo ao final do processo, resultados positivos no sentido da motivação para estudo do tema, envolvimentos dos alunos nas aulas e contribuição com um recurso didático efetivo.

PALAVRAS-CHAVE: Recursos didáticos. Atividades lúdicas. Nutrientes reguladores. Saúde. Jogos didáticos.

RESUMEN: Las actividades lúdicas son utilizadas en el proceso de la enseñanza aprendizaje de las diferentes áreas del conocimiento, por promovieron el aprendizaje de forma espontanea y divertida. Para el área de Ciencias agrarias, a cuál es un área multidisciplinar de estudios que pode ser abordada desde la enseñanza fundamental hasta la enseñanza media, hay la necesidad de estudios que visen la elaboración de recursos didácticos. De esta manera, este estudio objetivó el desarrollo de un juego

${ }^{1}$ Universidade de São Paulo (USP), Piracicaba - SP - Brasil. Escola Superior de Agricultura Luiz de Queiroz - (ESALQ). Graduanda do curso de Engenharia Agronômica e Licenciatura em Ciências Agrárias. E-mail: barbara.antonia@usp.br.

${ }^{2}$ Universidade de São Paulo (USP), Piracicaba - SP - Brasil. Escola Superior de Agricultura Luiz de Queiroz - (ESALQ). Graduado em Engenharia Florestal pela ESALQ. E-mail: rodrigo.fujiwara6@gmail.com.

${ }^{3}$ Universidade de São Paulo (USP), Piracicaba - SP - Brasil. Escola Superior de Agricultura Luiz de Queiroz - (ESALQ). Docente do Departamento de Economia, Administração e Sociologia (LES). E-mail: rosebelly.esalq@usp.br. 
didáctico en el área de ciencias agrarias vuelvo para la enseñanza fundamental, cuja estrategia es auxiliar en la comprensión de los contenidos relacionados a composición química de alimentos, como foco en nutrientes reguladores. El juego SAN SAN fuera aplicado y evaluado con alumnos de la enseñanza fundamental de una escuela pública, trayendo al final del proceso, envolvimiento de los alumnos en las clases y contribución con un recurso didáctico efectivo.

PALABRAS CLAVE: Recursos didácticos. Actividades lúdicas. Nutrientes reguladores. Salud. Juegos didácticos.

ABSTRACT: Leisure activities are used in the learning teaching process of the different areas of knowledge, to promote learning spontaneously and fun. For the area of Agrarian Sciences, which is a multidisciplinary area of study that can be approached from basic education to higher education, it is necessary to study the elaboration of didactic resources. Thus, this study aimed at the development of a didactic game in the field of agricultural sciences aimed at elementary education, whose strategy is to help in the understanding of contents related to the chemical composition of foods, focusing on regulatory nutrients. The game SAN SAN was applied and evaluated with elementary school students of a public school, bringing to the end of the process, positive results in the sense of motivation to study the subject, involvement of students in classes and contribution with an effective didactic resource.

KEYWORDS: Didactic resources. Play activities. Regulatory nutrientes. Health. Didactic games.

\section{Introdução}

O uso de recursos didáticos diversificados se faz essencial no processo de ensino-aprendizagem, pois se relaciona ao desenvolvimento das capacidades cognitivas do aluno, já que estimulam nos estudantes a curiosidade, a observação, o questionamento e a participação. Ou seja, faz com que os alunos deixem de ser agentes passivos e se tornem agentes ativos de sua própria aprendizagem (SANTOS; BELMINO, 2016).

Segundo Souza (2007), recursos didáticos são materiais utilizados como auxílio no ensino-aprendizagem do conteúdo proposto e devem ser aplicados pelo professor a seus alunos, sendo que livros, apostilas, recursos audiovisuais (projetor de slides, vídeos, sistemas de áudio) e jogos são alguns exemplos. Para Santos e Belmino (2016) um dos recursos didáticos que têm sido constantemente utilizados pelos professores são os jogos, isso porque promovem a aprendizagem de forma espontânea, divertida e segura. Esta percepção dos professores está ligada ao conceito de ludicidade do qual os jogos são parte. Este conceito consiste na realização de uma atividade prazerosa que 
seja descomprometida com a realidade e que possua objetivos característicos e próprios que são atingidos e finalizados com ela (DOHME, 2003). Já para Luckesi (2005), a ludicidade está relacionada à propiciação de uma experiência plena, ou seja, a realização de uma atividade na qual o sujeito esteja inteira e exclusivamente envolvido com a mesma.

Neste contexto percebe-se que os jogos são atividades que têm sido utilizadas de forma satisfatória como recurso didático para o processo de ensino-aprendizagem. No entanto, para que se atinja a finalidade do uso de jogos em sala de aula é de fundamental importância que o professor deixe evidente aos alunos qual o objetivo a ser alcançado no final da atividade, bem como tenha conhecimento das regras e as evidencie aos alunos. Ademais, é essencial também que o professor realize o emprego dos jogos adequando-os corretamente à faixa etária, além de realizar o acompanhamento dos alunos durante o desenvolvimento da atividade.

Dessa forma é necessária a criação e o desenvolvimento de jogos educativos destinados as diferentes etapas de ensino (básico, fundamental, médio, técnico e superior) e relacionados às mais diversas áreas do conhecimento. Para algumas dessas áreas já existe um vasto repertório de jogos educativos que vêm sendo elaborados por professores e pesquisadores, como por exemplo, os desenvolvidos para o ensino de conteúdos de Matemática, Ciências, Biologia e Química. Brito (2014) e Moratori (2003) têm estudado o desenvolvimento de jogos relacionado à matemática através de sistemas informatizados. Já Miranda (2015) estudou o desenvolvimento de jogos para o ensino de química a alunos do programa para Educação de Jovens e Adultos (EJA). Ainda no ensino de química, Neves et al (2013) elaboraram o jogo Quidescoberta, porém para ser utilizado no ensino médio, sendo que a influência do uso de jogos para o ensino de química foi estudada por Santana (2008).

No entanto, para algumas áreas ainda se faz necessário estudos que visem à elaboração de jogos educativos aplicados a essas áreas, como por exemplo, a área de Ciências Agrárias. Esta é uma área multidisciplinar de estudos que visam à segurança alimentar, investindo no aprimoramento técnico para aumentar a produção e a produtividade agropecuária, com melhorias no manejo que contribuam para o uso sustentável dos recursos naturais, envolvendo os campos da Agronomia, Agroecologia, Zootecnia, Engenharia florestal e de pesca e Ciências dos alimentos (MARINHO, 2016). Um exemplo de jogo que já existe para essa área é chamado Spórus, o qual é voltado para o ensino do tema sementes para alunos de nível técnico (PEREIRA Jr. et 
al, 2014).

Entretanto, alguns conteúdos de Ciências Agrárias podem ser trabalhados não somente nos ensinos técnico e superior, mas também nas outras etapas de ensino, desde que realizada uma adequação à faixa etária. Um desses conteúdos refere-se à composição química dos alimentos, o qual em cursos de nível técnico e superior pode ser estudado do ponto de vista da Bioquímica (Agronomia), da Nutrição Animal (Zootecnia) e da Nutrição Humana (Ciências dos alimentos).

Já em cursos de ensino médio é estudado nas disciplinas contidas na área de Ciências da Natureza, matemática e suas tecnologias conforme recomendações dos Parâmetros Curriculares Nacionais (PCN's) e nos cursos de ensino fundamental é estudado nas disciplinas contidas na área de Ciências Naturais. Segundo os PCN's, o ensino da composição química dos alimentos para o ensino fundamental deve ocorrer nas séries do $4^{\circ}$ ciclo $\left(7^{\mathrm{a}}\right.$ série $/ 8^{\circ}$ ano e $8^{\mathrm{a}}$ série $/ 9^{\circ}$ ano) e deve ser abordado nos conteúdos Ser Humano e Saúde. No $8^{\circ}$ ano a sugestão é de que seja abordado como um conteúdo central através do qual serão desenvolvidos conceitos, procedimentos e atitudes:

Distinção de alimentos que são fontes ricas de nutrientes plásticos, energéticos e reguladores, caracterizando o papel de cada grupo no organismo humano, avaliando sua própria dieta, reconhecendo as consequências de carências nutricionais e valorizando os direitos do consumidor (BRASIL, 1998).

Já para o $9^{\circ}$ ano sugere-se que o conteúdo seja abordado de forma contextualizada com tópicos do corpo humano, sendo o principal deles o fornecimento de energia a partir dos alimentos e sua relação com o metabolismo. Os trechos que apresentam essas sugestões nos Parâmetros Curriculares Nacionais para terceiro e quarto ciclo do ensino fundamental - Ciências Naturais são apresentados a seguir (BRASIL, 1998, p. 102):

São introduzidos com maior ênfase no quarto ciclo estudos sobre o aproveitamento da energia dos alimentos [...]

Considerando-se que os estudantes já compreendem os alimentos como fonte de energia e substâncias para o corpo [...]

[...] os estudantes podem compreender que o aproveitamento dos alimentos depende de processos que ocorrem em todas as células [...]

Já no Currículo Oficial do estado de São Paulo, o qual é baseado nos PCN's, o tema também deve ser abordado no $8^{\circ}$ ano dentro do eixo Ser humano e Saúde, sob o 
título de Manutenção do organismo. O Caderno do Aluno que é distribuído em todas as escolas estaduais de São Paulo e é em baseado no Currículo Oficial do estado de SP traz o tema para o $8^{\circ}$ ano, no volume 1 , na situação de aprendizagem 1, sob o título de $O$ que estamos comendo - os nutrientes.

Observando se alguns livros didáticos para o $8^{\circ}$ ano, é possível visualizar que o conteúdo é apresentado principalmente na forma de tabelas e/ou tópicos. A maior parte dos livros observados abordava o conteúdo de forma resumida, sendo que os apresentaram mais informações ainda assim não eram completos.

Com base no cenário apresentado, este trabalho visa relatar as etapas de elaboração, aplicação e avaliação de um jogo educativo para o ensino fundamental, cuja estratégia é auxiliar na compreensão dos conteúdos relacionados à composição química de alimentos, com foco em nutrientes reguladores.

\section{Metodologia}

A construção e aplicação de um jogo educativo voltado ao ensino fundamental foi uma atividade desenvolvida para a disciplina LES0342 - Instrumentação para o ensino de Ciências Agrárias, do curso de Licenciatura em Ciências Agrárias da ESALQ/USP. Para o desenvolvimento dessa atividade participaram alunos do $8^{\circ}$ e $9^{\circ}$ do ensino fundamental de uma escola pública do estado de São Paulo. Inicialmente, essa atividade envolveu as observações das aulas de Ciências desses alunos, a partir das quais se determinou o tema do jogo educativo. Segundo Ludke e André (2012), é necessário que se faça o planejamento da observação através da delimitação do objeto de estudo. Nesse caso, delimitou se a observação ao conteúdo ministrado nas aulas, os alunos e o ambiente escolar no qual eles estavam inseridos.

O desenvolvimento do jogo foi realizado em quatro etapas: avaliação de conhecimentos prévios, construção do jogo (protótipo e versão final), aplicação e avaliação final. Segundo Pozo (1998), conhecimentos prévios são todos os conhecimentos, corretos ou não, que cada sujeito tem e que foi adquirido ao longo de sua vida a partir da interação com o mundo ao seu redor e com a escola. Dessa forma, a avaliação feita com os alunos visou conhecer quais são os conhecimentos prévios sobre composição química dos alimentos que eles têm, sendo que isso foi feito através de observação direta e da aplicação de um questionário aos alunos, o qual é apresentado na figura 1. 
Figura 1: Questionário para avaliação de conhecimentos prévios

\section{QUESTIONÁRIO INICIAL}

\section{Dona Joana está com Anemia. Ela está com falta de qual nutriente?}

(A) Cálcio (B) Potássio (C) Ferro (D) Vitamina K

1. Seu José está com dificuldade para enxergar em ambiente com pouca luz. Ele está com deficiência de qual tipo de nutriente?

(A) Vitaminas (B) Proteínas (C) Substâncias ópticas (D) Carboidratos

Fonte: Elaboração própria

Em seguida, iniciou-se a construção do jogo, sendo que primeiramente elaborou se um protótipo, o qual teve por objetivo validar as mecânicas do jogo e suas regras. Os testes foram efetuados com estudantes de graduação e com pessoas fora do ambiente acadêmico. Utilizou-se da observação direta como método de análise do jogo e de acordo com os comentários e sugestões dos jogadores foram feitas alterações no jogo. De acordo com as adequações discutidas na avaliação do protótipo elaborou-se a versão final do jogo utilizando se os materiais definitivos.

A construção tanto do protótipo quanto da versão final foi feita utilizando materiais de baixo custo e fácil acesso. As cartas e o tabuleiro foram criados utilizandose o software Microsoft Office Excel e logotipo foi criado através do site Online Logo Maker. Os componentes do jogo foram confeccionados através de impressão em papel sulfite $75 \mathrm{~g} / \mathrm{m}^{2}$. O protótipo utilizou tanto para as cartas quanto para o tabuleiro papel sulfite na cor branca e impressão em preto e branco, já a versão final utilizou para as cartas papel sulfite na cor amarela e impressão em preto e branco e para o tabuleiro papel sulfite na cor branca e impressão colorida. Também para a versão final, ambos os componentes foram plastificados a fim de garantir um melhor estado de conservação e aspecto estético.

O jogo desenvolvido recebeu o nome de SAN SAN e é composto por dois blocos de cartas e dez tabuleiros. Cada bloco possui 80 cartas dispostas em 20 conjuntos, sendo que cada conjunto se refere a um nutriente regulador. Dessa forma, cada conjunto é composto por quatro cartas, sendo que cada uma refere-se a um tipo de informação: nome do nutriente regulador, função, alimentos que contém esse nutriente e informações adicionais. 
Para a aplicação desse jogo, os alunos foram divididos em grupos. Cada grupo recebeu um tabuleiro e quatro conjuntos de cartas, ou seja, 16 cartas embaralhadas, e com base em uma introdução sobre o tema ministrada no início da aula e com o auxílio do livro didático, solicitou se que identificassem quais cartas apresentavam informações sobre o mesmo nutriente regulador e que as colocassem nos espaços correspondentes do tabuleiro, sendo que cada coluna do tabuleiro correspondia a uma das informações. Após os alunos completarem o tabuleiro, eles deveriam chamar o professor que indicaria se estava certo ou não. Em caso negativo, o professor forneceria uma dica que auxiliava os alunos na resolução. O jogo terminou quando todos os grupos completaram corretamente o tabuleiro.

Além da observação direta como método de análise da aplicação do jogo em sua versão final, foi realizada uma avaliação, a qual consistiu na reaplicação de uma das questões do questionário aplicado inicialmente (avaliação de conhecimentos prévios) e em uma questão aberta para coletar as opiniões dos alunos sobre o uso do jogo como recurso didático. O questionário de avaliação final é apresentado na figura 2.

Figura 2: Questionário para avaliação final

QUESTIONÁRIO FINAL
1. Dificuldade de enxergar pode ser causada por
deficiência de:
(A) Carboidratos (B) Vitaminas (C) Sais Minerais (D) lipídios
1. O que você achou da aula? Comente.

Fonte: Elaboração própria

\section{Resultados}

As observações realizadas nas aulas de Ciências dos $8^{\circ}$ e $9^{\circ}$ anos permitiram conhecer o conteúdo ministrado nas aulas, os alunos e o ambiente escolar no qual eles estavam inseridos. As observações foram realizadas durante o segundo semestre do ano letivo. Durante as aulas observadas, os alunos estavam sendo preparados para o vestibular de escolas técnicas através da resolução de questões de provas de vestibulares anteriores, sendo que nessas aulas pôde ser observada a dificuldade da maior parte dos alunos nas questões relacionadas ao tema Composição química dos alimentos. 
Entretanto, segundo relatos da professora responsável pela disciplina de Ciências, durante o primeiro semestre deste mesmo ano, conforme recomendação do Currículo Oficial do Estado de São Paulo, os alunos de $8^{\circ}$ ano tiveram o assunto de forma conceitual e os alunos do $9^{\circ}$ ano tiveram o conteúdo de forma contextualizada. Tendo em vista a dificuldade dos alunos no aprendizado deste conteúdo da área de Ciências Agrárias foi proposto o desenvolvimento de um jogo educativo que auxiliasse no processo de ensino-aprendizagem da Composição química dos alimentos.

Para isso, inicialmente foi aplicado um questionário de conhecimentos prévios, através do qual pode se concluir que $75 \%$ dos alunos tinham conhecimento sobre um dos problemas causados pela deficiência de Ferro. No entanto, apenas $40 \%$ dos alunos disseram saber que a cegueira noturna (dificuldade de enxergar em ambientes pouco iluminados) estava relacionada à deficiência de uma vitamina. Após a aplicação do questionário, os alunos puderam comentar as questões da avaliação e segundo o relato de alguns alunos, eles sabiam que a Anemia era um problema causado pela deficiência de Ferro, pois esse é um problema relativamente comum na população brasileira e por isso bem conhecido. Já a cegueira noturna, muitos não se lembravam do assunto ter sido comentado em aula nem de já ter ouvido falar sobre isso em qualquer outro local (família, amigos, meios de comunicação, etc). Alguns dos alunos que acertaram a questão disseram se lembrar do conteúdo sendo comentado em aula. Os resultados são apresentados na tabela 1 .

Tabela 1: Porcentagem de alunos que acertarem as questões 1 e 2 do questionário inicial.

\begin{tabular}{cc}
\hline Questão & $\begin{array}{c}\% \text { de } \\
\text { acertos }\end{array}$ \\
\hline 1 & 75,0 \\
2 & 40,2 \\
\hline
\end{tabular}

Fonte: Elaboração Própria

Com a relação à construção do jogo, primeiramente foi realizado a elaboração do protótipo, através da seleção de conteúdo e confecção dos componentes do jogo. $\mathrm{O}$ conteúdo para a construção das cartas do protótipo foi retirado de três diferentes livros didáticos para $8^{\circ}$ ano. No entanto, durante o processo de seleção desse conteúdo pôde se observar uma alta discrepância entre as afirmações que cada livro didático trazia. Dessa 
forma, para a elaboração da versão final, o conteúdo foi revisado utilizando livros de ensino superior na área de Ciências Agrárias, tal como Princípios de Bioquímica (LEHNINGER, A.L.; 1991) e Biodisponibilidade de nutrientes (COZZOLINO, S.M.F.; 2009). Com relação aos componentes, inicialmente foi criado o logotipo para o jogo, o qual faz referência a algumas das fontes de nutrientes reguladores bem como apresenta o nome do jogo (Figura 3).

Figura 3: Logotipo do jogo SAN SAN.

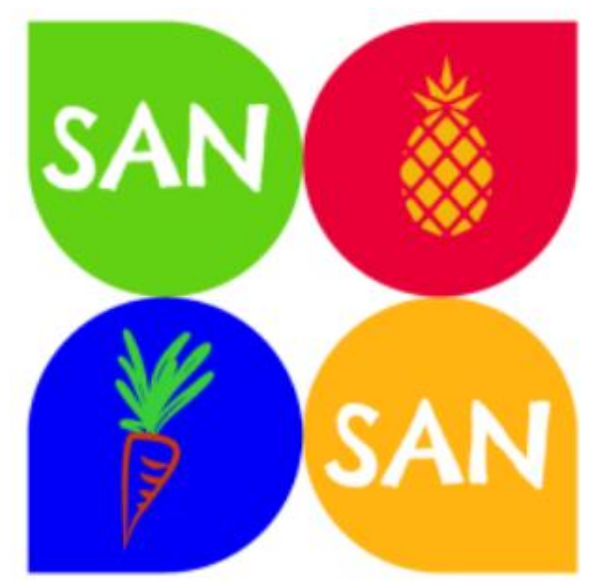

Fonte: Elaboração própria

Já em relação ao tamanho dos componentes, as cartas do protótipo tinham a dimensão de 5,5 x 7,5 cm e o tabuleiro de $27,3 \times 38,9 \mathrm{~cm}$. Foi sugerido pelos participantes do teste de avaliação do protótipo que elas tivessem o tamanho reduzido para facilitar a disposição das mesmas no tabuleiro e consequentemente proporcionar um melhor arranjo estético. Dessa forma, as cartas foram modificadas para o novo tamanho: 4,8 x 6,4 cm. O tamanho desconsidera a bordadura oriunda da plastificação das cartas. As duas versões são apresentadas na figura 4. 
Figura 4: Adequação das dimensões da carta: Carta do protótipo (A) e carta do jogo final (B).

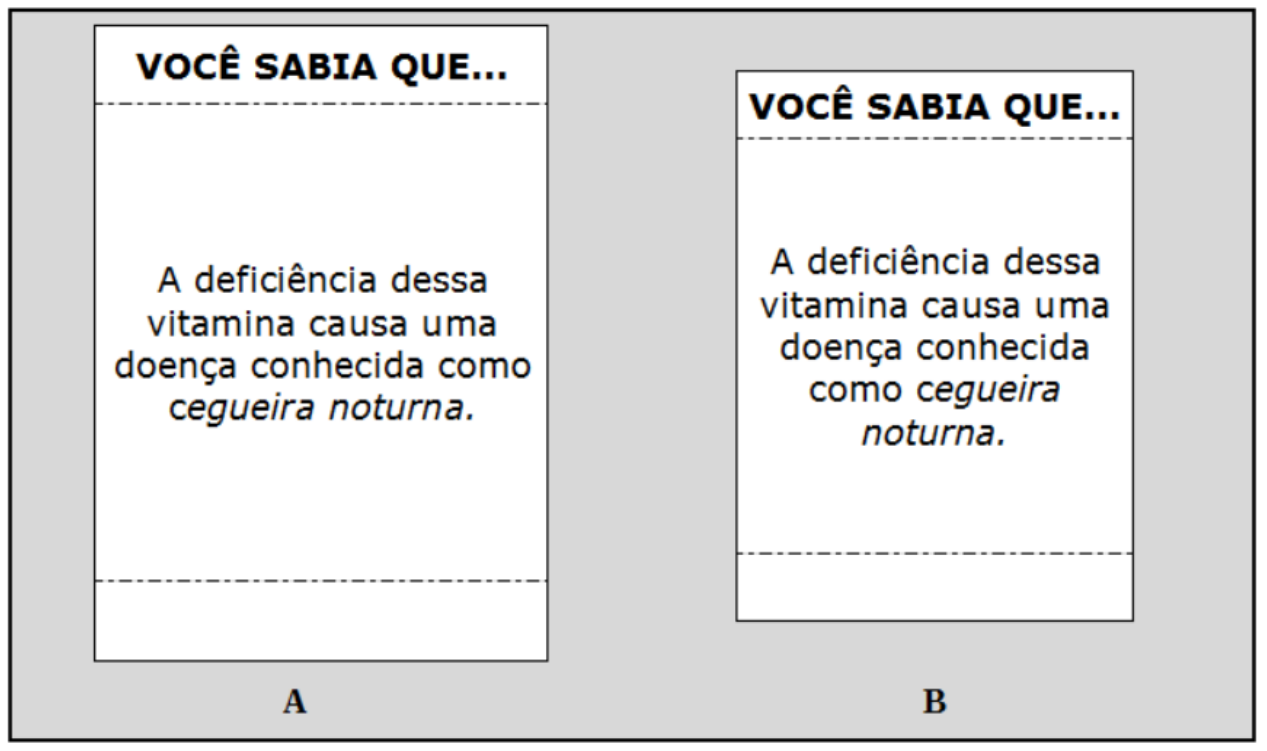

Fonte: Elaboração própria

Já em relação aos tabuleiros a sugestão realizada foi com relação à cor. $\mathrm{O}$ tabuleiro elaborado como protótipo, apesar de impresso em preto e branco, na versão digital era colorido predominantemente com a cor vermelha (Figura 5). Adequando-se às sugestões foram elaborados três novos modelos de tabuleiro, conforme apresentado na figura 6.

Figura 5: Tabuleiro do protótipo (predominantemente vermelho).

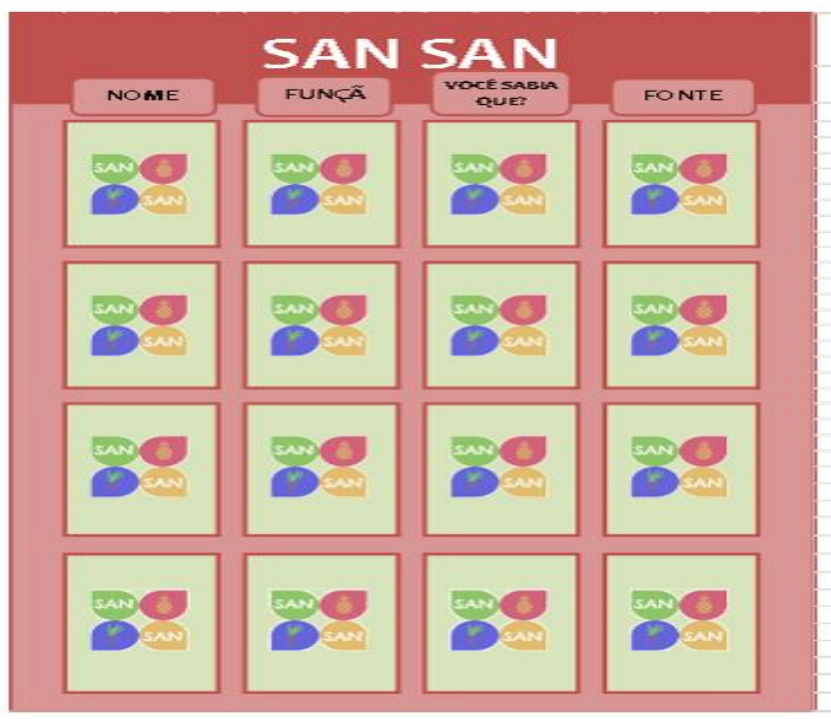

Fonte: Elaboração própria

Temas em Educ. e Saúde, Araraquara, v.13, n.2, p. 301-316, jul./dez. 2017. 
Figura 6 - Modelos de tabuleiro do jogo final
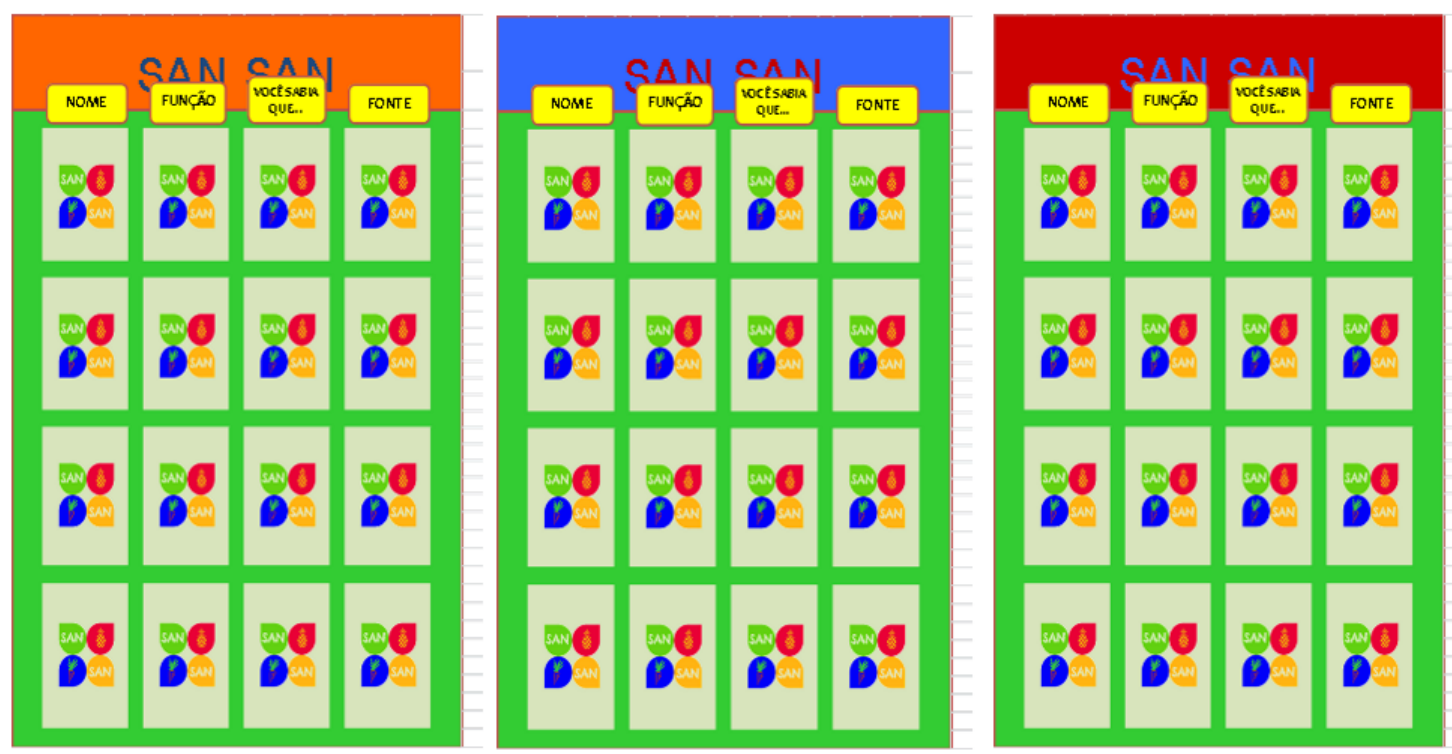

Fonte: Elaboração própria

Dessa forma, o jogo final, o qual foi confeccionado em papel sulfite e posteriormente plastificado é apresentando na figura 7 .

Figura 7: Jogo final: quatro conjuntos de cartas dispostas sobre o tabuleiro.

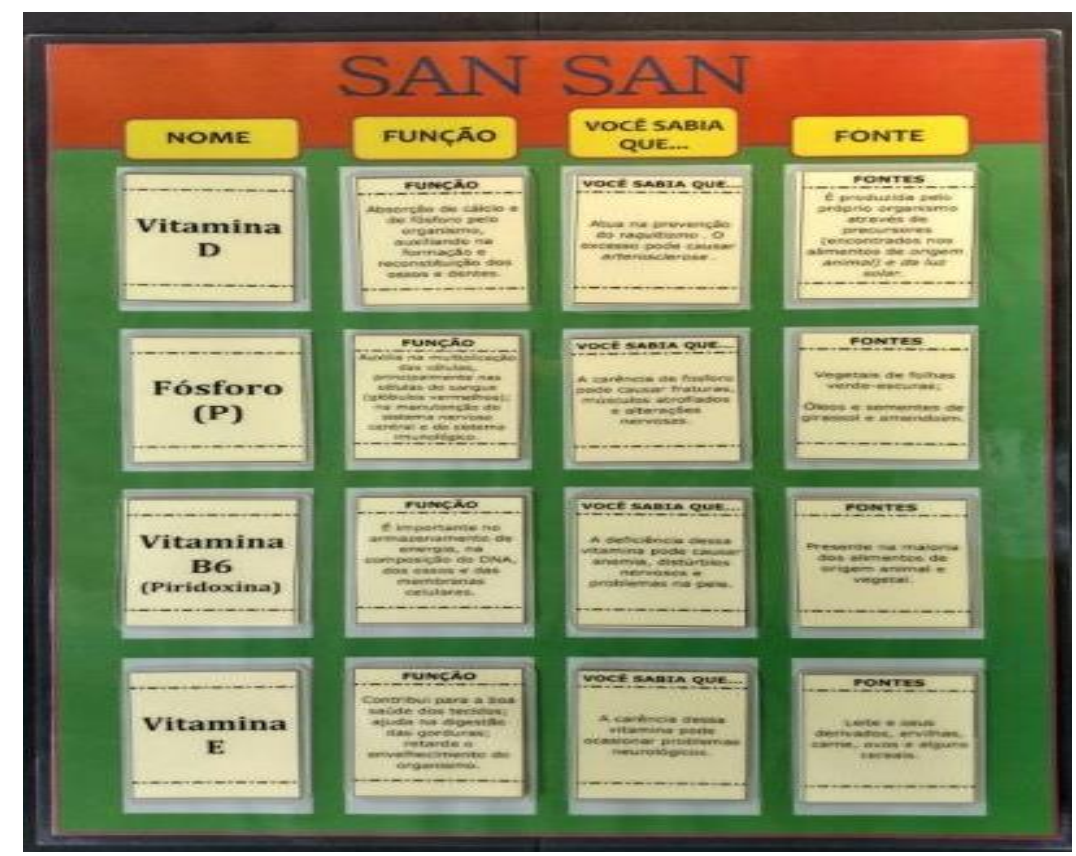

Fonte: Elaboração própria 
A aplicação do jogo foi realizada em turmas de $8^{\circ}$ e $9^{\circ}$ ano do ensino fundamental de uma escola pública do estado de São Paulo. As turmas tinham em média 35 alunos. Foi observado que o desenvolvimento do jogo foi melhor quando os alunos foram divididos em grupos de três ou quatro alunos. Se divididos em dupla, os alunos precisavam de um tempo maior para a resolução do jogo, além de que o número de peças do jogo se tornava insuficiente para atender uma classe com aproximadamente 35 alunos. No entanto, se os grupos tivessem mais do que quatro alunos, tornava-se difícil ao professor o controle da disciplina enquanto o jogo estava sendo aplicado.

Além disso, após a aplicação do jogo na primeira turma, houve a necessidade de criação de duas regras que foram preestabelecidas para as demais turmas. A primeira regra referia-se ao fato de que o grupo só poderia chamar o professor quando tivessem realmente completado o tabuleiro. Essa regra foi colocada, pois na primeira turma os alunos chamavam pelo professor a todo tempo mesmo não tendo completado o tabuleiro. A intenção dos alunos ao chamar o professor era de que o professor fornecesse a resposta a eles através de dicas. No entanto, os alunos tinham o livro didático e o caderno para realizar a pesquisa, dessa forma, a intervenção do professor da maneira como os alunos desejavam não se fazia necessária.

A segunda regra referia-se a correção do tabuleiro. Ao completar o tabuleiro e o professor realizar a correção, se houvesse erros, os alunos deveriam refazê-lo, sendo que o professor forneceria uma dica para a correção e só poderia ser chamado por este grupo novamente após todos os outros grupos terem chamado o professor. Ou seja, a correção era feita em um sistema de rodadas. Essa regra foi necessária, pois na primeira turma logo após o professor fornecer uma dica para correção, os alunos simplesmente trocavam as cartas de lugar aleatoriamente, num sistema de tentativa e erro, e chamavam o professor para a correção constantemente até chegar à posição correta das cartas. No entanto, limitando-se as correções feitas pelo professor, os alunos sentiram se estimulados a procurar mais uma vez a resposta para completar corretamente.

A implantação dessas regras tornou mais justa a competitividade do jogo, principalmente pelo fato de que a frequência das correções e consequentemente do fornecimento de dicas era a mesma para cada grupo e independente da velocidade de pesquisa de cada grupo. Dessa forma, os alunos perceberam que não era inteligente realizar uma pesquisa rápida visando a chamar logo o professor e obter a dica. Isso porque outro grupo poderia demorar mais na pesquisa, fazendo com que a rodada demorasse mais, e que quando o professor fosse chamado por aquele grupo para realizar 
a correção não fossem encontrados erros, fazendo com que aquele grupo fosse o vencedor.

Além disso, essas novas regras facilitaram a aplicação do jogo para o professor. Isso porque sem elas, apesar de possuírem os materiais para consulta, os alunos eram totalmente dependentes do professor. Essa dependência por parte de todos os alunos fazia com que o professor não conseguisse atender a todos ao mesmo tempo da mesma maneira. Ademais, sem as novas regras o jogo não estava atingindo um de seus objetivos, que é tornar o aluno um agente ativo em seu processo de aprendizagem.

Ao final foi aplicada uma avaliação com uma questão objetiva similar a do questionário inicial e uma questão aberta. Em relação à questão objetiva, a qual se referia à dificuldade de enxergar em ambientes pouco iluminados por deficiência de vitaminas, 90,1\% dos alunos acertaram a resposta. Isso significa que houve um aumento percentual de 49,9\% como pode ser observado na tabela 2 .

Tabela 2: Porcentagem de alunos que acertaram a questão que tinha como tema central "dificuldade de enxergar em ambientes com pouca luz causada por deficiência de vitaminas" no questionário inicial e final.

\begin{tabular}{cc}
\hline Questão & \% de acertos \\
\hline Inicial & 40,2 \\
Final & 90,1 \\
\hline
\end{tabular}

Fonte: Elaboração própria

Além disso, através das observações diretas e das respostas para a questão aberta pode-se concluir que os alunos gostaram do jogo, principalmente por tornar a aula mais divertida. Os alunos se referiram ao uso do jogo como uma forma interessante e educativa para o aprendizado. Além disso, o tema do jogo também foi bastante apreciado pelos alunos. Outro fator citado pelos alunos e que comprovou o objetivo do jogo é em relação à capacidade do jogo em tornar os alunos agentes ativos no processo de aprendizagem.

\section{Considerações finais}


O jogo educativo SAN SAN atendeu aos objetivos, já que facilitou o processo de ensino aprendizagem dos alunos na temática de nutrientes reguladores, conforme pode ser observado através das observações diretas e das respostas dos alunos ao questionário da avaliação final. Além disso, a elaboração de um protótipo previamente a elaboração do jogo final mostrou-se eficaz quanto aos parâmetros estéticos do jogo. No entanto, quanto às regras só pode se fazer as corretas adequações durante a aplicação, isso porque o público com o qual o protótipo foi testado e o público para o qual o jogo foi aplicado possuem comportamentos diferentes. Essas atitudes comportamentais dos alunos de ensino fundamental afetam o jogo quanto ao cumprimento do seu objetivo e à competitividade entre os jogadores, dessa forma, foi necessário o estabelecimento de regras que garantissem esses dois princípios no decorrer do jogo.

AGRADECIMENTOS: Agradecemos ao monitor da disciplina LES0342 Instrumentação para o ensino de Ciências Agrárias, do curso de Licenciatura em Ciências Agrárias da ESALQ/USP, Alex de Almeida, pelo auxílio no levantamento das informações presentes no jogo, bem como sua participação em diversas etapas de criação do mesmo.

\section{REFERÊNCIAS}

BRASIL. Ministério da Educação e do Desporto. Secretaria de Educação Fundamental. Parâmetros curriculares nacionais terceiro e quarto ciclos do ensino fundamental: ciências naturais. Brasília, DF: MEC/SEF, 1998.

BRITO, W. A. T. Modelo de recomendação de jogos baseado em seleção de conteúdo no ensino da matemática. 2014. 237 f. Dissertação (mestrado em informática) - Universidade Federal do Rio de Janeiro. Rio de Janeiro, 2014.

COZZOLINO, S. M. F. Biodisponibilidade de nutrientes. 3 ed. Barueri, SP: Manole, 2009.

DOHME, V. Atividades lúdicas na educação: o caminho de tijolos amarelos no aprendizado. Petrópolis: Vozes, 2003.

LEHNINGER, A. L. Princípios de bioquímica. São Paulo: Sarvier, 1991.

LUCKESI, C. C. Ludicidade e atividades lúdicas: uma abordagem a partir da experiência interna. Ludicidade: o que é mesmo isso, p. 22-60, 2005.

LUDKE, M.; ANDRÉ, M. E. D. A. Pesquisa em educação: abordagens qualitativas. São Paulo: E. P. U., 2012. 
MARINHO, E. O. C. Ciências Agrárias: o que é. Disponível em: $<$ http://proficiencia.org.br/ rubrique.php3?id_rubrique=43>. Acesso em: $09 \mathrm{dez}$ 2016.

MIRANDA, A. F. S. Jogos pedagógicos no processo de ensino e aprendizagem em química na modalidade educação de jovens e adultos. 2015. 126 f. Dissertação (Mestrado em educação em ciências e matemática) - Universidade Federal de Goiás. Goiânia, 2015.

MORATORI, P. B. Por que utilizar jogos educativos no processo de ensino aprendizagem? Trabalho de conclusão da disciplina introdução à informática na educação, no Mestrado de Informática aplicada à Educação da Universidade Federal do Rio de Janeiro.

NEVES, A. M. et al. Quídescoberta: o uso do lúdico no processo de ensino aprendizagem de química. Anais do IX Congresso de Iniciação Científica do IFRN. 2013.

PEREIRA JR, E. V.; MARQUES, R. N.; CHAGAS, I. H. Jogos didáticos: uma metodologia facilitadora no ensino de Ciências agrárias. Anais - V Jornada das Licenciaturas da USP/IX Semana da Licenciatura em Ciências Exatas - SeLic: A Universidade Pública na Formação de Professores: ensino, pesquisa e extensão. São Carlos, 2014.

POZO, J. I. A solução de problemas: aprender a resolver, resolver para aprender. Porto Alegre: ArtMed, 1998.

SANTANA, E. M. Influência de atividades lúdicas na aprendizagem de conceitos químicos. Anais do Seminário Nacional de Educação profissional e tecnologia. Belo Horizonte, 2008.

SANTOS, O. K. C.; BELMINO, J. F. B. Recursos didáticos: uma melhoria na qualidade da aprendizagem. Disponível em:

<http://editorarealize.com.br/revistas/fiped/trabalhos/Trabalho_ Comunicacao_oral_idinscrito_fde094c18ce8ce27adf61aedf31dd2d6.pdf >. Acesso em: 09 dez. 2016.

SÃO PAULO. Secretaria da Educação. Proposta curricular do Estado de São Paulo para o ensino de ciências para o ensino fundamental Ciclo II. São Paulo: SE, 2008.

SOUZA, S. E. O uso de recursos didáticos no ensino escolar. In: I Encontro de Pesquisa em Educação, IV Jornada de Prática de Ensino, XIII Semana de Pedagogia da UEM: "Infância e Práticas Educativas". Arq Mudi. 2007. 


\section{Como citar este artigo:}

ANTONIA, Bárbara Della.; FUJIWARA, Rodrigo Iwata.; MARQUES, Rosebelly Nunes. O jogo San San como recurso didático de apoio nas discussões sobre nutrientes reguladores no ensino fundamental. Temas em Educ. e Saúde, Araraquara, v.13, n.2, p. 301-316, jul./dez. 2017. Disponível em: <https://doi.org/10.26673/rtes.v13.n2.juldez.2017.10679>. E-ISSN: 2526-3471.

Submetido em: 20/05/2017

Aprovado em: 20/09/2017 